\title{
Nitric oxide-cGMP-PKG signaling in the bed nucleus of the stria terminalis modulates the cardiovascular responses to stress in male rats
}

\author{
Lucas Barretto-de-Souza ${ }^{\mathrm{a}, \mathrm{b}}$, Mariane B. Adami ${ }^{\mathrm{a}}$, \\ Leandro A. Oliveira ${ }^{a, b}$, Lucas Gomes-de-Souza ${ }^{a, b}$, \\ Josiane O. Duarte ${ }^{a}$, Jeferson Almeida ${ }^{a, b}$, Carlos C. Crestani ${ }^{a, b, *}$
}

a Laboratory of Pharmacology, São Paulo State University (UNESP), School of Pharmaceutical Sciences, Araraquara, SP, Brazil

'Joint UFSCar-UNESP Graduate Program in Physiological Sciences, São Carlos, SP, Brazil

Received 23 June 2017; received in revised form 29 October 2017; accepted 9 November 2017

\author{
KEYWORDS \\ BNST; \\ Stress; \\ Blood pressure; \\ Heart rate; \\ Sympathetic; \\ Guanylate cyclase
}

\begin{abstract}
The bed nucleus of the stria terminalis (BNST) constitutes an important component of neural substrates of physiological and behavioral responses to aversive stimuli, and it has been implicated on cardiovascular responses evoked by stress. Nevertheless, the local neurochemical mechanisms involved in BNST control of cardiovascular responses during aversive threats are still poorly understood. Thus, the aim of the present study was to assess the involvement of activation in the BNST of the neuronal isoform of the enzyme nitric oxide synthase (nNOS), as well as of signaling mechanisms related to nitric oxide effects such as soluble guanylate cyclase (sGC) and protein kinase $\mathrm{G}$ (PKG) on cardiovascular responses induced by an acute session of restraint stress in male rats. We observed that bilateral microinjection of either the nonselective NOS inhibitor N $\omega$-Nitro-L-arginine methyl ester (L-NAME), the selective nNOS inhibitor $\mathrm{N} \omega$-Propyl-L-arginine (NPLA) or the SGC inhibitor $1 \mathrm{H}-[1,2,4]$ Oxadiazolo[4,3-a]quinoxalin-1-one (ODQ) into the BNST enhanced the tachycardic response and decreased the drop in tail cutaneous temperature evoked by acute restraint stress, but without affecting the increase on blood pressure. Bilateral BNST treatment with the selective PKG inhibitor KT5823 also facilitated the heart rate increase and decreased the drop in cutaneous temperature, in addition to enhancing the blood pressure increase. Taken together, these results provide evidence that NO released from nNOS and activation of SGC and PKG within the BNST play an
\end{abstract}

\footnotetext{
*Correspondence to: Laboratory of Pharmacology, Department of Natural Active Principles and Toxicology, School of Pharmaceutical Sciences, São Paulo State University - UNESP, Rodovia Araraquara-Jau Km 01, 14800-903 Araraquara, SP, Brazil. Fax: +55 1633016980.

E-mail address: cccrestani@yahoo.com.br (C.C. Crestani).
} 
inhibitory influence on tachycardia to stress, whereas this signaling mechanism mediates the sympathetic-mediated cutaneous vasoconstriction.

(c) 2017 Elsevier B.V. and ECNP. All rights reserved.

\section{Introduction}

Physiological responses evoked during aversive situations are triggered by overlapping limbic circuits in the central nervous system (Dampney, 2015; Myers, 2017; Ulrich-Lai and Herman, 2009). The bed nucleus of stria terminalis (BNST) is a limbic structure located in the prosencephalon, which has been implicated in cardiovascular, neuroendocrine and behavioral responses to stress (Crestani et al., 2013; Davis et al., 2010). Specifically regarding the cardiovascular responses, it was demonstrated that reversible inactivation of the BNST enhanced the heart rate (HR) increase evoked by an acute session of restraint stress, but without affecting the blood pressure increase (Crestani et al., 2009). These results indicated an inhibitory role of the BNST on cardiac responses evoked by unconditioned aversive stimuli (Crestani et al., 2013). Conversely, a facilitatory role of the BNST on blood pressure and HR changes induced by contextual fear conditioning has been reported (Hott et al., 2012; Hott et al., 2017; Resstel et al., 2008). Taken together, these pieces of evidence suggested that role of the BNST regulating cardiovascular responses to stress is related to paradigm of aversive stimulus (e.g., conditioned versus unconditioned) (Crestani et al., 2013). Previous studies reported a role of local typical neurotransmitters in BNST control of cardiovascular responses to aversive threats, such as glutamate, acetylcholine and noradrenaline (Adami et al., 2017; Crestani et al., 2009; Gouveia et al., 2016; Hott et al., 2012, 2017). However, evidence of a possible involvement of atypical neurotransmitters, such as nitric oxide (NO), is still scarce.

The NO is synthesized from l-arginine by three isoforms of the enzyme nitric oxide synthase (NOS), which are called neuronal (nNOS), endothelial (eNOS) and induced (iNOS) (Alderton et al., 2001). The nNOS is proposed as the major isoform involved in the synthesis of $\mathrm{NO}$ in the brain (Garthwaite, 2008; Huang et al., 1993; Zhou and Zhu, 2009), and is widely expressed in mammalian encephalon (Bredt et al., 1991; Garthwaite, 2008; Vincent and Kimura, 1992). The activation of the soluble guanylate cyclase (sGC) enzyme, which converts guanosine triphosphate (GTP) to cyclic guanosine monophosphate (CGMP), has been described as the main pathway related to NO effects (Garthwaite, 2008). Despite the report of other signaling pathways (Craven and Zagotta, 2006; Rybalkin et al., 2003), the activation of the protein kinase $G$ (PKG) is a prominent effector mechanism of cGMP (Garthwaite, 2008; Hofmann et al., 2006).

Neurons capable of synthesizing NO were identified within the BNST (Vincent and Kimura, 1992), and these neurons are activated by aversive stimuli (Guimaraes et al., 2005). Furthermore, systemic administration of nNOS inhibitors attenuated the neuronal activation in the BNST induced by an aversive stimulus (Silva et al., 2012), thus providing evidence that nNOS in the BNST is activated during stress. Previous studies evidenced a role of nNOS within the BNST in the control of baroreflex activity (Alves et al., 2009) and of cardiovascular responses to contextual fear conditioning (Hott et al., 2017). However, an involvement of signaling mechanisms related to NO effects, such as cGMP-PKG pathway, in BNST control of cardiovascular function has never been investigated. Furthermore, evidence of a role of BNST nitrergic neurotransmission in control of cardiovascular responses to unconditioned aversive stimulus is missing. Therefore, this study aimed to evaluate the hypothesis that activation of $\mathrm{nNOS}$, SGC and PKG within the BNST modulate the cardiovascular responses evoked by an acute session of restraint stress in male rats.

\section{Experimental procedures}

\subsection{Animals}

Male Wistar rats with body weight ranging from 240 to $260 \mathrm{~g}$ were used. The animals were supplied by the animal breeding facility of the UNESP (Botucatu, SP, Brazil). The animals had free access to granulated feed and water, and were submitted to alternating light/dark cycles (lights on between 7:00 h a.m. and 7:00 h p.m.). All experimental procedures were carried out following protocol approved by Ethical Committee for Use of Animals (CEUA) of the School of Pharmaceutical Science/UNESP (protocol \# 10/2013), which complies with Brazilian and international guidelines for animal use and welfare.

\subsection{Surgical preparation}

Five days before the trial, animals were anesthetized with tribromoethanol $(250 \mathrm{mg} / \mathrm{kg}$, i.p.), scalp was anesthetized with $2 \%$ lidocaine, and the skull was exposed. Then, using a stereotaxic apparatus (Stoelting, Wood Dale, Illinois, USA), stainless-steel cannulas (26G, $12 \mathrm{~mm}$ long) were bilaterally implanted into the BNST. Stereotaxic coordinates were: antero-posterior $=+8.6 \mathrm{~mm}$ from interaural; lateral $=4.0 \mathrm{~mm}$ from the medial suture, ventral $=-5.8 \mathrm{~mm}$ from the skull, with a lateral inclination of $23^{\circ}$ (Paxinos and Watson, 1997). Dental cement was used to fix cannulas to the skull. After surgery, the rats were treated with a poly-antibiotic containing streptomycins and penicillins to prevent infection $(560 \mathrm{mg} / \mathrm{mL} / \mathrm{kg}$, i.m.) and the nonsteroidal anti-inflammatory flunixine meglumine to provide post-operation analgesia $(0.5 \mathrm{mg} / \mathrm{mL} / \mathrm{kg}$, s.c. $)$.

One day before the experiment, animals were again anesthetized with tribromoethanol $(250 \mathrm{mg} / \mathrm{kg}$, i.p.) and a polyethylene cannula (a $4 \mathrm{~cm}$ segment of PE-10 bound to a $13 \mathrm{~cm}$ segment of PE50) (Clay Adams, Parsippany, New Jersey, USA) was implanted into the abdominal aorta via the femoral artery for cardiovascular recording. The catheter was tunneled under the skin and exteriorized on the animal's dorsum. After the surgery, the nonsteroidal 
anti-inflammatory flunixine meglumine was administered for postoperation analgesia $(0.5 \mathrm{mg} / \mathrm{mL} / \mathrm{kg}$, s.c. $)$. The animals were kept in individual cages during the post-operative period and cardiovascular recording.

\subsection{Arterial pressure and HR recording}

The catheter implanted into the abdominal aorta via the femoral artery was connected to a pressure transducer (DPT100, Utah Medical Products Inc., Midvale, UT, USA). Pulsatile arterial pressure was recorded using an amplifier (Bridge Amp, ML221, ADInstruments, Australia), connected to a computerized data acquisition system (PowerLab 4/30, ML866, ADInstruments, Australia) using an appropriate program (Lab Chart PRO, ADInstruments, Australia). The values of mean arterial pressure (MAP) and heart rate (HR) were obtained from the pulsatile arterial pressure recordings.

\subsection{Tail cutaneous temperature measurement}

Tail skin temperature records were performed using a thermal camera Multi-Purpose imager (IRI4010, InfraRed Integrates Systems Ltd, Northampton, UK). The analysis was performed using a software for thermographic analysis, and temperature was represented by color intensity variations (Busnardo et al., 2013; Vianna and Carrive, 2005). For image analysis, the temperature values were obtained at 5 points along the animal's tail, and the mean was calculated for each recording.

\subsection{Restraint stress}

Acute restraint stress consisted of introducing the animals into plastic cylindrical tubes (diameter $=6.5 \mathrm{~cm}$, length $=15 \mathrm{~cm}$ ), which were ventilated by $1 / 2$ inch holes that comprised approximately $20 \%$ of the tube. In the present study, restraint stress session lasted 30 min (Adami et al., 2017; Choi et al., 2007; Crestani et al., 2010b), after which animals were returned to their home cage. Each animal was submitted to only one session of stress in order to avoid habituation.

\subsection{Drug microinjection into the brain}

Injection needles (33G, Small Parts, USA) used for the microinjection of drugs into the BNST were one $\mathrm{mm}$ longer than the guide cannulas fixed to the skull. The needle was connected to a two $\mu \mathrm{L}$ syringe $(7002 \mathrm{KH}$, Hamilton, USA) using a PE-10 tubing. The drugs were injected in a final volume of $100 \mathrm{~nL}$ (Adami et al., 2017; Crestani et al., 2010a; Crestani et al., 2009).

\subsection{Drugs and solutions}

$\mathrm{N} \omega$-Nitro-L-arginine methyl ester hydrochloride (L-NAME) (SigmaAldrich, St Louis, Missouri, USA), N $\omega$-Propyl-L-arginine hydrochloride (NPLA) (TOCRIS, Westwoods Business, Park Ellisville, MO, USA), tribromoethanol (Sigma-Aldrich) and urethane (Sigma-Aldrich) were dissolved in saline $(\mathrm{NaCl} 0.9 \%) .1 \mathrm{H}-[1,2,4]$ Oxadiazolo[4,3-a]quinoxalin-1-one (ODQ) (TOCRIS) and KT5823 (TOCRIS) were dissolved in a solution of saline containing $20 \%$ of DMSO (DMSO 20\%). Flunixine megulimine (Banamine, Schering Plough, Cotia, SP, Brazil) and the polyantibiotic preparation of streptomycins and penicillins (Pentabiótico, Fort Dodge, Campinas, SP, Brazil) were used as provided.

\subsection{Experimental design}

Rats were brought to the experimental room in their own cage at least 60 minutes before starting the experiment. The experimental room was temperature controlled $\left(24^{\circ} \mathrm{C}\right)$ and acoustically isolated from the others rooms.

Independent set of animals received bilateral microinjections into the BNST of either the nonselective NOS inhibitor N $\omega$-Nitro-Larginine methyl ester (L-NAME, $40 \mathrm{nmol} / 100 \mathrm{~nL}$ ), the selective nNOS inhibitor N $\omega$-Propyl-L-arginine (NPLA, $0.4 \mathrm{nmol} / 100 \mathrm{~nL}$ ), the sGC inhibitor ODQ $(1 \mathrm{nmol} / 100 \mathrm{~nL})$, the selective PKG inhibitor KT5823 $(0.1 \mathrm{nmol} / 100 \mathrm{~nL})$ or vehicles (either saline or DMSO $20 \%$, $100 \mathrm{~nL}$ ). Doses of the inhibitors were based on previous studies from our group (Alves et al., 2009; Busnardo et al., 2010; Hott et al., 2017).

Ten minutes after the pharmacological treatment of the BNST, animals in all experimental groups were subjected to a 30-minute session of restraint stress. Blood pressure and heart rate recordings started at least 30 minutes before the onset of the stress session, and were performed throughout the restraint stress period. Tail skin temperature was measured at 10,5 and 0 min before the restraint, and every 5 min during the stress session.

\subsection{Histological determination of the microinjection sites}

At the end of each experiment, all animals were anesthetized with urethane $(250 \mathrm{mg} / \mathrm{mL} / 200 \mathrm{~g}$ body weight, i.p. $)$ and $100 \mathrm{~nL}$ of $1 \%$ Evan's blue dye was injected into the brain at the same volume of drug injection (i.e., $100 \mathrm{~nL}$ ) as a marker of microinjection sites. The brains were then removed from the cranial cavity and postfixed in $10 \%$ formalin solution for at least $48 \mathrm{~h}$ at $4{ }^{\circ} \mathrm{C}$. Then, serial $40 \mu \mathrm{m}$ thick sections of the BNST region were cut using a cryostat (CM1900, Leica, Wetzlar, Germany). The sites of injection sites were analyzed using the Atlas of Paxinos and Watson (1997) as reference.

\subsection{Statistical analysis}

Data are presented as mean \pm standard error of the mean (SEM). The basal values of MAP, HR, and tail skin temperature were compared using Student's $t$-test. The time-course curves of cardiovascular changes during restraint stress were analyzed using twoway analysis of variance (ANOVA), with treatment as main factor and time as repeated measurement, followed by Bonferroni posthoc test. The significance was set at $P<0.05$.

\section{Results}

Figure 1 presents diagrammatic representations showing microinjection sites into the BNST of L-NAME, NPLA, ODQ, KT5823 and vehicle of all animals used in the present study. A photomicrograph of a coronal brain section depicting microinjection sites in the BNST of a representative animal is also presented in Figure 1.

\subsection{Effect of bilateral microinjection of L-NAME into the BNST on cardiovascular responses to acute restraint stress}

Bilateral microinjection of the nonselective NOS inhibitor L-NAME (40nmol/100nL, $n=7$ ) into the BNST did not affect the baseline values of either MAP $(107 \pm 1 \mathrm{vs} 108 \pm 3 \mathrm{mmHg}, t$ $=0.4, P>0.05), \mathrm{HR}(362 \pm 17$ vs $377 \pm 8 \mathrm{bpm}, t=0.8, P>$ $0.05)$ or cutaneous temperature of the tail $(27.4 \pm 0.7$ vs 25.9 $\left.\pm 0.6{ }^{\circ} \mathrm{C}, t=1.4, P>0.05\right)$, when compared with the animals that received vehicle into the BNST $(n=6)$. However, acute 


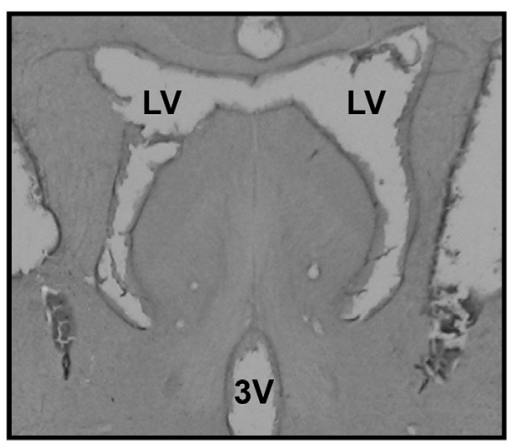

L-NAME

IA 8.74

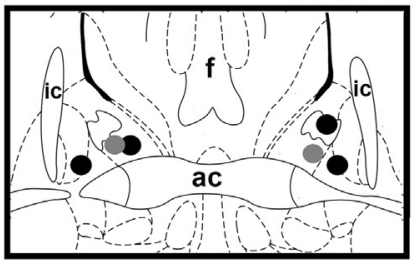

IA 8.60
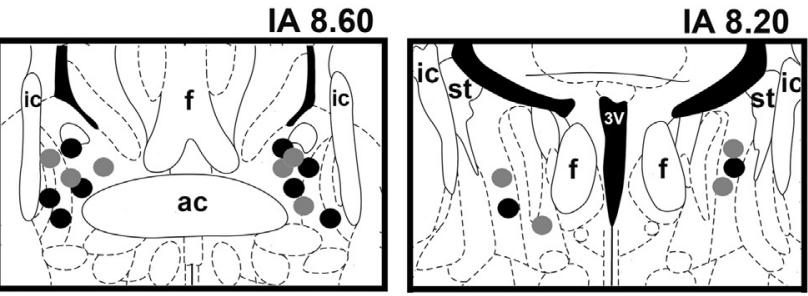

NPLA
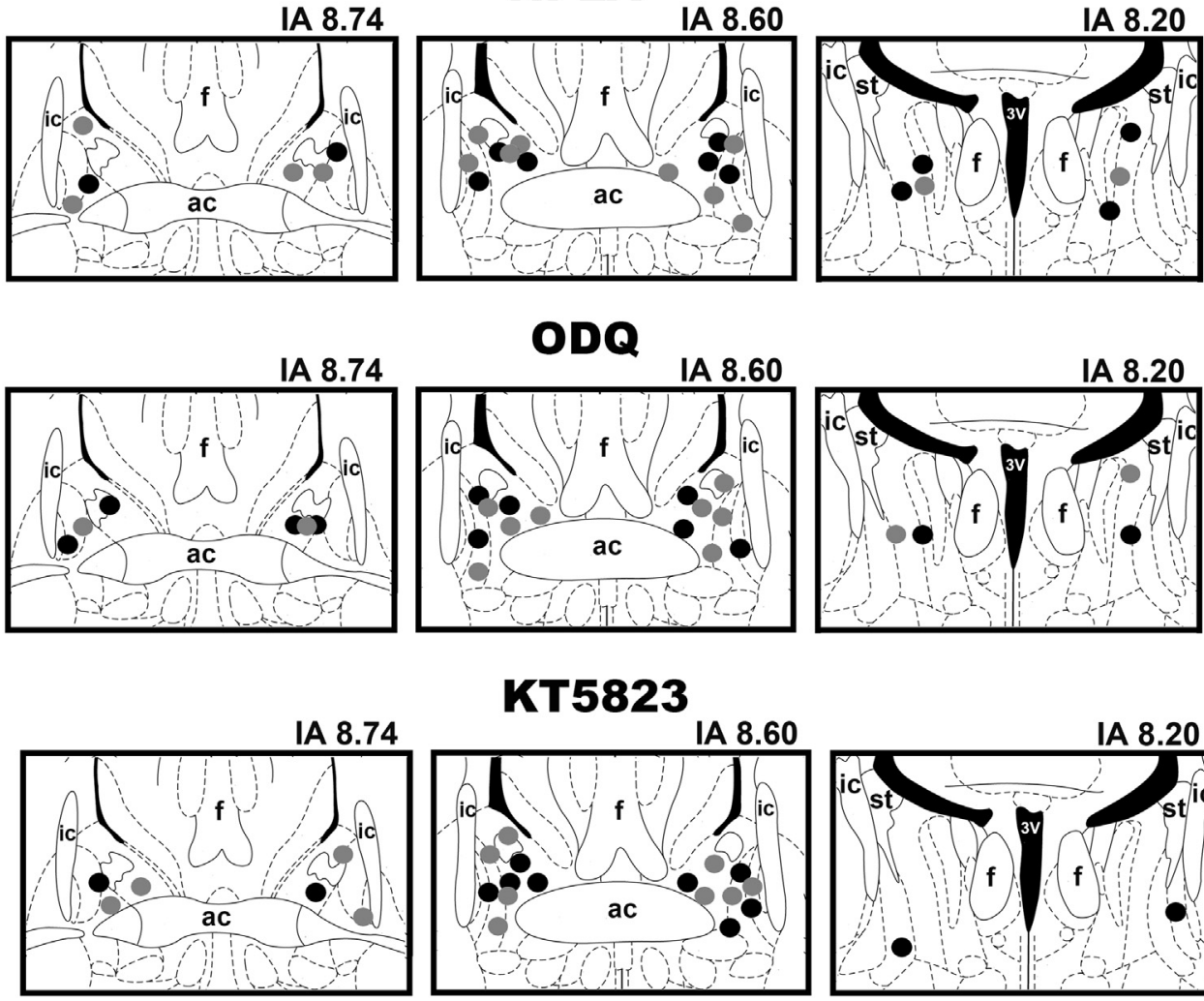

KT5823
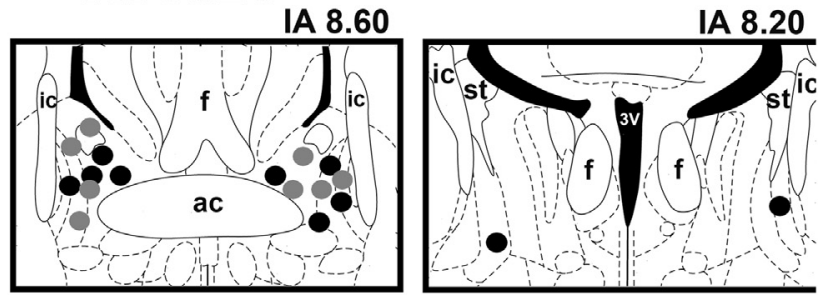

Figure 1 (Top) Photomicrograph of a coronal brain section depicting microinjection sites in the BNST of a representative animal. (Bottom) Diagrammatic representation based on the rat brain atlas of Paxinos and Watson (1997) indicating the microinjection sites into the BNST of vehicle (gray circles) and the nonselective NOS inhibitor L-NAME (black circles, first panel), the selective nNOS inhibitor NPLA (black circles, second panel), the SGC inhibitor ODQ (black circles, third panel) and the selective PKG inhibitor KT5823 (black circles, fourht panel). $3 \mathrm{~V}$ - third ventricle, ac - anterior commissure; $f$ - fornix; IA - interaural coordinate; ic - internal capsule; LV - lateral ventricle; st - stria terminalis.

restraint stress evoked a sustained increase on both MAP $\left(F_{(19,220)}=17, P<0.0001\right)$ and $\operatorname{HR}\left(F_{(19,220)}=17\right.$, $P<0.0001)$, and decreased the tail skin temperature $\left(F_{(8,99)}\right.$ $=6, P<0.0001$ ) (Figure 2). Besides, treatment of the BNST with L-NAME enhanced the tachycardiac response $\left(F_{(1,220)}=20\right.$, $P<0.0001)$ and decreased the drop on skin temperature $\left(F_{(1,99)}=6, P<0.01\right)$ evoked by restraint, but without affecting the pressor response $\left(F_{(1,220)}=0.3, P>0.05\right)$ 


\section{L-NAME}
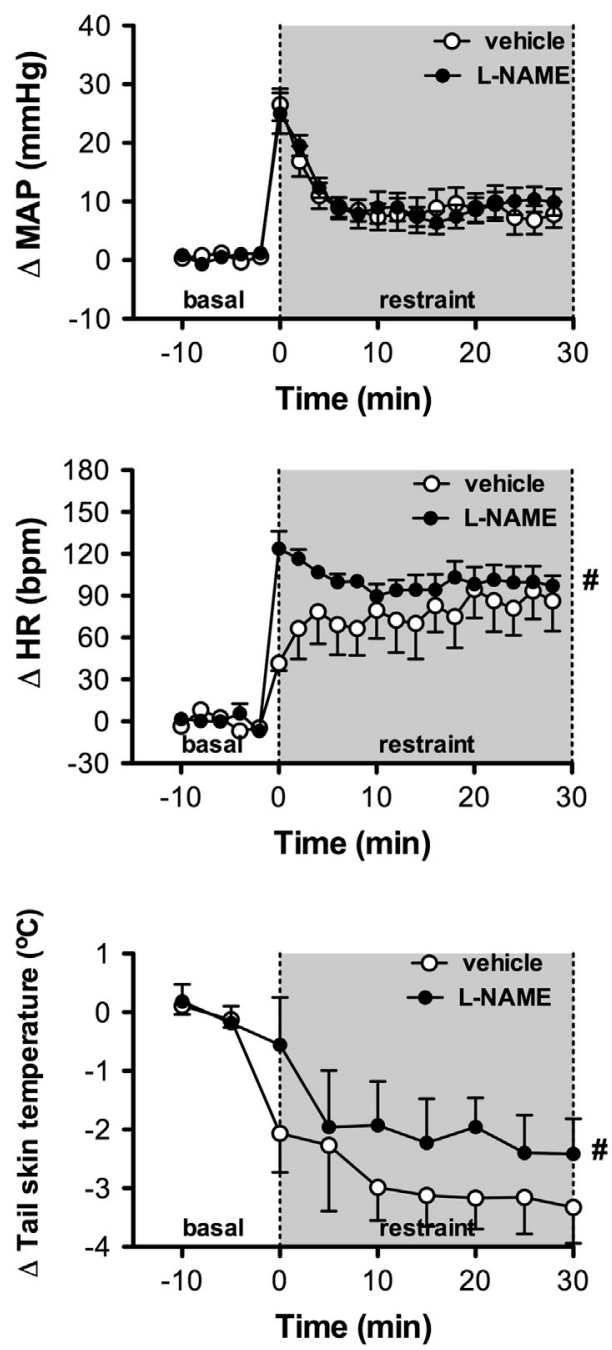

NPLA
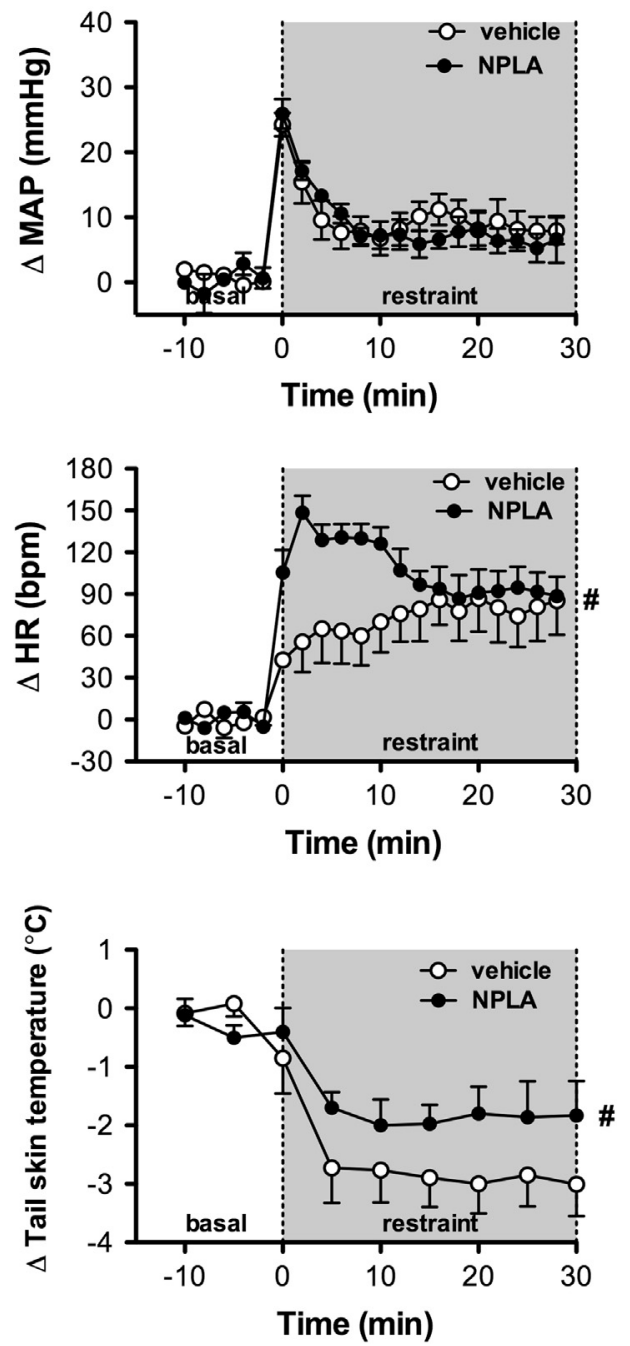

Figure 2 Effect of BNST treatment with inhibitors of NOS on cardiovascular responses to acute restraint stress. (Left) Time-course curves of change on mean arterial pressure $(\triangle M A P)$, heart rate $(\triangle H R)$ and tail skin temperature $(\Delta$ tail skin temperature) evoked by acute restraint stress in animals treated bilaterally into the BNST with the nonselective NOS inhibitor L-NAME (40 nmol/100 nl, $n=7$ ) or vehicle (100 nL, $n=6$ ). (Right) Time-course curves of $\Delta M A P, \Delta$ HR and $\Delta$ tail skin temperature evoked by acute restraint stress in animals treated bilaterally into the BNST with the selective nNOS inhibitor NPLA $(0.4 \mathrm{nmol} / 100 \mathrm{nl}, n=6)$ or vehicle $(100 \mathrm{~nL}$, $n=6)$. The onset of stress was at $t=0$. Circles represent the mean and the bars the SEM. \# $P<0.05$ over the whole restraint period compared to vehicle-treated animals, ANOVA followed by Bonferroni post-hoc test.

(Figure 2). Analysis did not indicate significant treatment $x$ time interaction for either $\operatorname{MAP}\left(F_{(19,220)}=0.3, P>0.05\right)$, HR $\left(F_{(19,220)}=1, P>0.05\right)$ or cutaneous temperature $\left(F_{(8,99)}=\right.$ $0.3, P>0.05)$.

\subsection{Effect of bilateral microinjection of NPLA into the BNST on cardiovascular responses to acute restraint stress}

Bilateral treatment of the BNST with the selective nNOS inhibitor NPLA $(0.4 \mathrm{nmol} / 100 \mathrm{~nL}, n=6)$ did not affect the baseline values of either MAP (106 \pm 1 vs $107 \pm 2 \mathrm{mmHg}, t$ $=0.1, P>0.05), \mathrm{HR}(376 \pm 8$ vs $384 \pm 11 \mathrm{bpm}, t=0.6, P$ $>0.05)$ or tail skin temperature $(27.3 \pm 0.7$ vs $28.4 \pm$ $\left.0.6{ }^{\circ} \mathrm{C}, t=1.2, P>0.05\right)$, when compared with the animals that received vehicle into the BNST $(n=6)$. However, acute restraint stress caused a sustained increase on both MAP $\left(F_{(19,200)}=15, P<0.0001\right)$ and $\operatorname{HR}\left(F_{(19,200)}=12\right.$, $P<0.0001)$, and decreased the cutaneous temperature of the tail $\left(F_{(8,90)}=11, P<0.0001\right)$ (Figure 2$)$. Moreover, treatment of the BNST with NPLA enhanced the tachycardiac response $\left(F_{(1,200)}=27, P<0.0001\right)$ and decreased the drop on tail skin temperature $\left(F_{(1,90)}=9, P<0.003\right)$ evoked by restraint stress, but whithout affecting the increase on MAP $\left(F_{(1,200)}=1, P>0.05\right)$ (Figure 2$)$. Analysis also indicated a significant treatment $x$ time interaction for $\operatorname{HR}\left(F_{(19,200)}=2, P<0.02\right)$, but not for $\operatorname{MAP}\left(F_{(19,200)}=0.6\right.$, $P>0.05)$ and cutaneous temperature $\left(F_{(8,90)}=0.9\right.$, $P>0.05)$. 

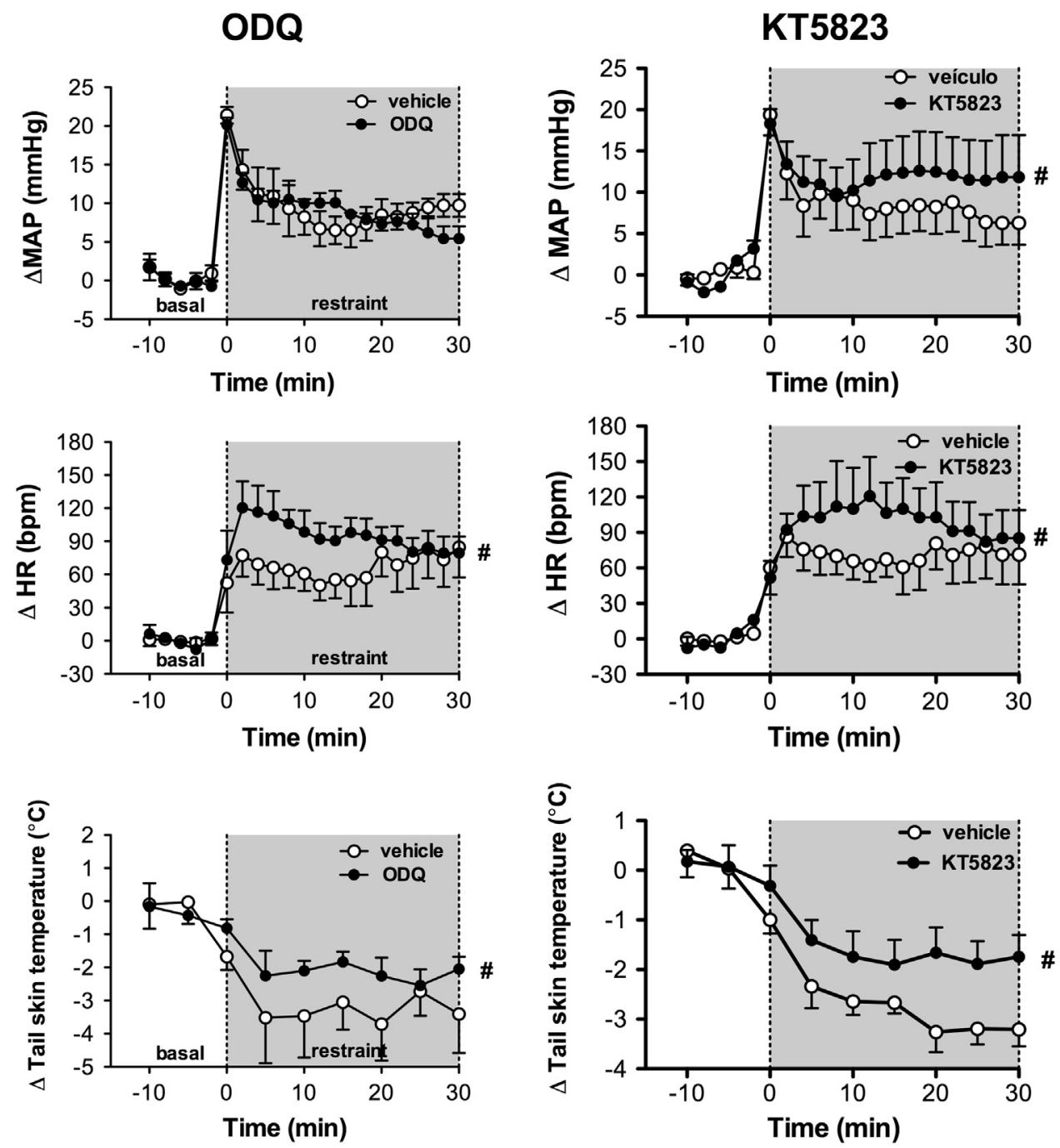

Figure 3 Effect of BNST treatment with inhibitors of either sGC or PKG on cardiovascular responses to acute restraint stress. (Left) Time-course curves of change on mean arterial pressure $(\triangle M A P)$, heart rate $(\Delta H R)$ and tail skin temperature $(\Delta$ tail skin temperature) evoked by acute restraint stress in animals treated bilaterally into the BNST with the sGC inhibitor ODQ (1 nmol/ $100 \mathrm{nl}, n=6)$ or vehicle $(100 \mathrm{~nL}, n=6)$. (Right) Time-course curves of $\Delta$ MAP, $\Delta$ HR and $\Delta$ tail skin temperature evoked by acute restraint stress in animals treated bilaterally into the BNST with the selective PKG inhibitor KT5823 $(0.1 \mathrm{nmol} / 100 \mathrm{nl}, n=6)$ or vehicle $(100 \mathrm{~nL}, n=6)$. The onset of stress was at $t=0$. Circles represent the mean and the bars the SEM. \# $P<0.05$ over the whole restraint period compared to vehicle-treated animals, ANOVA followed by Bonferroni post-hoc test.

\subsection{Effect of bilateral microinjection of ODQ into the BNST on cardiovascular responses to acute restraint stress}

Bilateral treatment of the BNST with the SGC inhibitor ODQ $(1 \mathrm{nmol} / 100 \mathrm{~nL}, n=6)$ did not affect the baseline values of either MAP (103 \pm 4 vs $99 \pm 3 \mathrm{mmHg}, t=0.8, P>0.05)$, HR $(357 \pm 7$ vs $366 \pm 9 \mathrm{bpm}, t=0.7, P>0.05)$ or tail skin temperature $\left(29.0 \pm 0.6\right.$ vs $29.9 \pm 0.5{ }^{\circ} \mathrm{C}, t=1$, $P>0.05)$, when compared with animals that received vehicle into the BNST $(n=6)$. However, acute restraint stress caused a sustained increase on both MAP $\left(F_{(19,200)}=\right.$ $17, P<0.0001)$ and $\operatorname{HR}\left(F_{(19,200)}=8, P<0.0001\right)$, and decreased the cutaneous temperature $\left(F_{(8,90)}=4, P<\right.$ 0.0004) (Figure 3). Moreover, treatment of the BNST with ODQ enhanced the tachycardiac response $\left(F_{(1,200)}=15\right.$, $P<0.0002$ ) and decreased the drop on tail skin temperature $\left(F_{(1,90)}=4, P<0.03\right)$ evoked by restraint, but whithout affecting the increase on $\operatorname{MAP}\left(F_{(1,200)}=0.6\right.$, $P>0.05)$ (Figure 3). Analysis did not indicate a significant treatment $x$ time interaction for both $\operatorname{MAP}\left(F_{(19,200)}=0.6\right.$, $P>0.05)$, HR $\left(F_{(19,200)}=0.7, P>0.05\right)$ and cutaneous temperature $\left(F_{(8,90)}=0.4, P>0.05\right)$.

\subsection{Effect of bilateral microinjection of KT5823 into the BNST on cardiovascular responses to acute restraint stress}

Bilateral treatment of the BNST with the selective PKG inhibitor KT5823 $(0.1 \mathrm{nmol} / 100 \mathrm{~nL}, n=6)$ did not affect the baseline values of either MAP (107 \pm 3 vs $108 \pm$ $3 \mathrm{mmHg}, t=0.3, P>0.05), \operatorname{HR}(356 \pm 18$ vs $368 \pm$ $14 \mathrm{bpm}, t=0.5, P>0.05)$ or tail skin temperature $(27.0$ 
\pm 0.9 vs $\left.28.4 \pm 0.9{ }^{\circ} \mathrm{C}, t=1, P>0.05\right)$, when compared with the animals that received vehicle into the BNST ( $n=$ 6 ). However, acute restraint stress caused a sustained increase on both MAP $\left(F_{(19,200)}=5, P<0.0001\right)$ and $\mathrm{HR}$ $\left(F_{(19,200)}=6, P<0.0001\right)$, and decreased the cutaneous temperature of the tail $\left(F_{(8,90)}=15, P<0.0001\right)$ (Figure 3). Moreover, treatment of the BNST with KT5823 enhanced the restraint-evoked pressor $\left(F_{(1,200)}=6\right.$, $P<0.0004)$ and tachycardiac $\left(F_{(1,200)}=9, P<0.002\right)$ responses, and decreased the drop on tail skin temperature $\left(F_{(1,90)}=18, P<0.0001\right)$ (Figure 3$)$. Analysis did not indicate a treatment $x$ time interaction for both MAP $\left(F_{(19,200)}=0.3, P>0.05\right), \operatorname{HR}\left(F_{(19,200)}=0.4, P>0.05\right)$ and cutaneous temperature $\left(F_{(8,90)}=1, P>0.05\right)$.

Microinjection of either L-NAME, NPLA, ODQ or KT5823 into structures surrounding the BNST did not evoke any change in restraint-evoked cardiovascular responses (data not shown).

\section{Discussion}

The present study provides the first evidence for an involvelment of CGMP-PKG signaling on control of cardiovascular responses to aversive threats. Furthermore, results reported here are the first to indicate a role of BNST nitrergic signalling modulating the cardiovascular responses evoked by an unconditioned aversive stimulus. Indeed, we observed that BNST treatment with inhibitors of either the nNOS, sGC or PKG enhanced the tachycardiac response and decreased the drop in tail skin temperature evoked by acute restraint stress. Besides, PKG inhibition within the BNST enhanced the restraint-evoked pressor response.

With exception of the PKG inhibitor, any of the treatments affected the pressor response to restraint, despite of the increased tachycardiac response. The absence of changes on pressor response is possibly related to the decreased drop in tail skin temperature, so that a possible increase in cardiac output mediated by the facilitation of $\mathrm{HR}$ response was buffered by the decreased vasoconstriction in cutaneous bed. However, we cannot to exclude the possibility of a role of changes in other vascular beds since PKG inhibition enhanced the restraint-evoked pressor response even in presence of a decreased drop in tail skin temperature. Therefore, further studies are necessary to a better understanding of the role of BNST nitrergic neurotransmission in control of hemodynamic responses to stress.

The present data indicating an inhibitory influence of BNST nitrergic neurotransmission on stress-evoked cardiovascular changes contrasts with previous findings of pro-aversive effect of NO in the central nervous system, which was evidenced mainly by an involvement of NO in stress behavioral consequences (Calixto et al., 2008; Guimaraes et al., 2005; Silva et al., 2012). However, our results are in line with reports of protector cardiovascular effects of nitrergic neurotransmission in the central nervous system (Martins-Pinge et al., 2012; Patel and Zheng, 2012; Stern et al., 2003). Furthermore, changes on restraint-evoked cardiovascular responses following BNST treatment with the inhibitors of nNOS, SGC and PKG are similar to effects reported previously in animals subjected to BNST nonselective synaptic inactivation (Crestani et al., 2009). Indeed, we documented previously that bilateral BNST neurotransmission inhibition via local treatment with the nonselective synaptic blocker $\mathrm{CoCl}_{2}$ enhanced the restraintevoked tachycardia, but without affecting the pressor response (Crestani et al., 2009). Likewise, the HR increase during restraint stress was also enhanced by BNST treatment with either selective $\alpha_{1}$-adrenoceptor or muscarinic cholinergic receptor antagonists (Crestani et al., 2009; Gouveia et al., 2016). In this sense, present findings provide new evidence indicating a role of local release of $\mathrm{NO}$ from nNOS, and activation of SGC and PKG, in BNST inhibitory influence on cardiac responses to restraint stress. Furthermore, our findings corroborate reports of a facilitatory role of the BNST on sympathetically-mediated cutaneous vasoconstriction during aversive threats (Adami et al., 2017; Hott et al., 2012, 2017).

NO is synthetized from the l-arginine by the nNOS in the brain in response to influx of $\mathrm{Ca}^{2+}$ following activation of the $\mathrm{N}$-methyl-D-aspartate (NMDA) glutamatergic receptor (Garthwaite, 2008; Prast and Philippu, 2001). In this sense, Adami et al. (2017) reported recently that microinjection of a selective NMDA receptor antagonist into the BNST decreased the tachycardic response to acute restraint stress, thus suggesting a facilitatory influence of BNST glutamatergic neurotransmission on cardiac responses to restraint stress. Besides, blockade of NMDA glutamate receptor within the BNST did not affect the sympathetically-mediated cutaneous vasoconstriction (Adami et al., 2017). Therefore, the control of restraint-evoked cardiovascular responses by BNST nitrergic neurotransmission seems not to be related to an interaction with local glutamatergic neurotransmission. However, we cannot exclude the possibility that nNOS is activated in response to NMDA receptor activation in the BNST, but once released NO interacts with other local neurochemical mechanisms to control restraint-evoked cardiovascular responses. In this sense, activation of BNST NMDA receptor induces local release of noradrenaline (Aliaga et al., 1995; Forray and Gysling, 2004). Despite the absence of direct evidence of an interaction between BNST noradrenergic and nitrergic neurotransmissions, the similar modulation of cardiac response to restraint stress by nNOS and $\alpha_{1}$-adrenoceptor within the BNST (Crestani et al., 2009), together with evidence that NO act pre-synaptically stimulating neurotransmitter release (Garthwaite, 2008; Prast and Philippu, 2001), supports the hypothesis that BNST nitrergic signaling may acts through a facilitation of local release of noradrenaline. Nevertheless, considering that NO-cGMP-PKG pathway also acts post-synaptically directly depolarizing and hyperpolarizing neurons (Garthwaite, 2008; Prast and Philippu, 2001), we cannot rule out the possibility that BNST nitrergic neurotransmission modulates the cardiovascular responses to stress via mechanisms independent of interactions with other local neurochemical mechanisms. Anyway, further studies are necessary to clarify the local mechanisms related to modulation of cardiovascular responses to stress by NO-cGMP-PKG pathway within the BNST.

The inhibitory influence of BNST nitrergic signaling in control of restraint-evoked HR response contrasts with recent results indicating a facilitatory role of this neurochemical mechanism in control of cardiovascular responses to contextual fear conditioning (Hott et al., 2017). Nevertheless, the opposite role of BNST nitrergic signaling in control of cardiovascular responses to conditioned versus unconditioned 
stimuli is in line with previous evidence that BNST plays opposite roles in control of cardiovascular responses to unconditioned (inhibitory) and conditioned (facilitatory) aversive stimuli (Crestani et al., 2009; Resstel et al., 2008). A specific control of cardiovascular responses to conditioned versus unconditioned stimuli by BNST nitrergic neurotransmission is further supported by evidence of different neural circuitry and neurochemical/cellular mechanisms involved in expression of innate and conditioned defensive responses (Gross and Canteras, 2012; Rosen, 2004). In this sense, the BNST is part of brain circuits involved in expression of both conditioned and unconditioned responses (Gungor and Pare, 2016), but this structure seems to differently processes innate versus conditioned emotional information. It is possibly related to multiple functional subregions and group of cells within the BNST with different, or even opposite, functional phenotype (Gungor and Pare, 2016; Lebow and Chen, 2016). The multiple BNST connections also provide a neuroanatomical basis for elaboration of stressor-specific responses (Gungor and Pare, 2016; Lebow and Chen, 2016; Myers, 2017). Importantly, the NO signaling seems to be a prominent local neurochemical mechanism mediating the specific control of cardiovascular responses to unconditioned versus conditioned stimuli by BNST.

Outputs from corticolimbic structures such as the hippocampus, amygdala and medial prefrontal cortex (MPFC) converge on the BNST (Dong et al., 2001a; Myers et al., 2014). Besides, BNST neurons project to hypothalamic and brainstem nuclei controlling autonomic activity (Dong et al., 2001b; Dong and Swanson, 2006). Thus, since limbic structures such as amygdala, hippocampus, and MPFC have little direct anatomical connections with primary stress effector regions in hypothalamus and brainstem (Myers, 2017; Ulrich-Lai and Herman, 2009), the BNST has been proposed as a relay station between processing of emotional information by limbic forebrain structures and elaboration of physiological and behavioral responses to stress by hypothalamic and brainstem regions (Crestani et al., 2013; Myers, 2017; Ulrich-Lai and Herman, 2009). Supporting this idea, it was reported that MPFC lesion decreased restraintevoked activation of BNST neurons (Figueiredo et al., 2003). Additionally, inactivation of either the medial amygdaloid nucleus (MeA) or MPFC evoked effects in cardiovascular responses to restraint stress in which were similar to those presently reported (i.e., facilitation of tachycardia) (Fortaleza et al., 2009; Tavares et al., 2009). Thus, although evidence that limbic inputs to the BNST are predominantly glutamatergic and GABAergic (Myers et al., 2014), present findings indicate that local activation of nNOS, sGC and PKG are important in processing of limbic information in the BNST for elaboration of cardiovascular responses.

Cardiovascular responses during aversive threats are mediated by changes on activity of both sympathetic and parasympathetic nervous system (Crestani, 2016). For instance, increase on HR during aversive threats is abolished following inhibition of sympathetic tone to the heart while blockade of cardiac parasympathetic activity increases this response (Carrive, 2006; Dos Reis et al., 2014), thus suggesting that both sympathetic and parasympathetic tone to the heart are increased during stress (Crestani, 2016). The vasoconstriction in cutaneous beds, which in turn causes a drop in skin temperature (Busnardo et al., 2013;
Vianna and Carrive, 2005), is mediated by an increase of sympathetic vasomotor outflow (Blessing, 2003). Neurons within the BNST project to medullary structures controlling autonomic activity, such as the nucleus of the solitary tract, nucleus ambiguus, and ventrolateral regions (Dong and Swanson, 2004; Gray and Magnuson, 1987). Previous findings indicated an inhibitory influence of nNOS activation within the BNST on cardiac parasympathetic outflow (Alves et al., 2009). Therefore, the inhibitory role of NO released from nNOS, as well as of SCG and PKG activation, in the BNST on restraint-evoked tachycardia is possibly mediated by stimulation of inhibitory drive to sympathetic premotor neurons. Conversely, the decrease of sympathetic-mediated cutaneous vasoconstriction indicates activation of sympathetic circuits by nitrergic signaling within the BNST. The existence of specific neuronal pathways controlling autonomic activity to different organs provides the structural substrate for a different control of sympathetic activity to heart and cutaneous vascular beds during aversive threats by BNST nitrergic signaling (Morrison, 2001).

In summary, our data indicate an involvement of the activation of both nNOS, sGC and PKG within the BNST on cardiovascular responses during aversive threats. Specifically, present findings provide evidence of an inhibitory influence on tachycardiac response to stress, whereas the sympathetically-mediated cutaneous vasoconstriction is mediated by NO released from nNOS and activation of sGC and PKG within the BNST.

\section{Role of funding source}

Funding for this study was provided by FAPESP (grants \# 2012/ 14376-0 and 2015/05922-9) and CNPq (grant \# 456405/2014-3). The FAPESP and CNPq had no further role in study design; in the collection, analysis and interpretation of data; in the writing of the report; and in the decision to submit the paper for publication.

\section{Contributors}

L.B.S., M.B.A. and C.C.C. conceived and designed this research; L. B.S., M.B.A., L.A.O., L.G.S., J.O.D. and J.A. performed the experiments and analysed the data; L.B.S., M.B.A., L.A.O., L.G. S., J.O.D., J.A. C.C.C. interpreted the results of experiments; L.B. S. prepared the figures and drafted the manuscript; L.B.S. and C.C. C. edited and revised the manuscript; C.C.C. approved the final version of the manuscript.

\section{Conflict of interest}

The authors declare no conflicts of interest.

\section{Acknowledgements}

The authors wish to acknowledgement Elisabete Lepera and Rosana Silva for technical assistance. The present research was supported by grants from FAPESP (grants \# 2012/14376-0 and 2015/05922-9), CNPq (grant \# 456405/2014-3), and Scientific Support and Development Program of School of Pharmaceutical Sciences (UNESP). CCC is a CNPq research fellow (process \# 305583/2015-8). 


\section{References}

Adami, M.B., Barretto-de-Souza, L., Duarte, J.O., Almeida, J., Crestani, C.C., 2017. Both N-methyl-D-aspartate and non-N-methyl-Daspartate glutamate receptors in the bed nucleus of the stria terminalis modulate the cardiovascular responses to acute restraint stress in rats. J. Psychopharmacol. (269881117691468).

Alderton, W.K., Cooper, C.E., Knowles, R.G., 2001. Nitric oxide synthases: structure, function and inhibition. Biochem. J. 357, 593-615.

Aliaga, E., Bustos, G., Gysling, K., 1995. Release of endogenous catecholamines from the striatum and bed nucleus of stria terminalis evoked by potassium and $\mathrm{N}$-methyl-D-aspartate: in vitro microdialysis studies. J. Neurosci. Res. 40, 89-98.

Alves, F.H., Crestani, C.C., Resstel, L.B., Correa, F.M., 2009. Bed nucleus of the stria terminalis $\mathrm{N}$-methyl-D-aspartate receptors and nitric oxide modulate the baroreflex cardiac component in unanesthetized rats. J. Neurosci. Res. 87, 1703-1711.

Blessing, W.W., 2003. Lower brainstem pathways regulating sympathetically mediated changes in cutaneous blood flow. Cell Mol. Neurobiol. 23, 527-538.

Bredt, D.S., Glatt, C.E., Hwang, P.M., Fotuhi, M., Dawson, T.M., Snyder, S.H., 1991. Nitric oxide synthase protein and mRNA are discretely localized in neuronal populations of the mammalian CNS together with NADPH diaphorase. Neuron 7, 615-624.

Busnardo, C., Alves, F.H., Crestani, C.C., Scopinho, A.A., Resstel, L. B., Correa, F.M., 2013. Paraventricular nucleus of the hypothalamus glutamate neurotransmission modulates autonomic, neuroendocrine and behavioral responses to acute restraint stress in rats. Eur. Neuropsychopharmacol. 23, 1611-1622.

Busnardo, C., Crestani, C.C., Tavares, R.F., Resstel, L.B., Correa, F. M., 2010. Cardiovascular responses to L-glutamate microinjection into the hypothalamic paraventricular nucleus are mediated by a local nitric oxide-guanylate cyclase mechanism. Brain Res. 1344, 87-95.

Calixto, A.V., Duarte, F.S., Moraes, C.K., Faria, M.S., De Lima, T.C., 2008. Nitric oxide involvement and neural substrates of the conditioned and innate fear as evaluated in the T-maze test in rats. Behav. Brain Res. 189, 341-349.

Carrive, P., 2006. Dual activation of cardiac sympathetic and parasympathetic components during conditioned fear to context in the rat. Clin. Exp. Pharmacol. Physiol. 33, 1251-1254.

Choi, D.C., Furay, A.R., Evanson, N.K., Ostrander, M.M., Ulrich-Lai, Y.M., Herman, J.P., 2007. Bed nucleus of the stria terminalis subregions differentially regulate hypothalamic-pituitary-adrenal axis activity: implications for the integration of limbic inputs. J. Neurosci. 27, 2025-2034.

Craven, K.B., Zagotta, W.N., 2006. CNG and HCN channels: two peas, one pod. Annu Rev. Physiol. 68, 375-401.

Crestani, C.C., 2016. Emotional stress and cardiovascular complications in animal models: a review of the influence of stress type. Front Physiol. 7, 251.

Crestani, C.C., Alves, F.H., Correa, F.M., Guimaraes, F.S., Joca, S. R., 2010a. Acute reversible inactivation of the bed nucleus of stria terminalis induces antidepressant-like effect in the rat forced swimming test. Behav. Brain Funct. 6, 30.

Crestani, C.C., Alves, F.H., Gomes, F.V., Resstel, L.B., Correa, F.M., Herman, J.P., 2013. Mechanisms in the bed nucleus of the stria terminalis involved in control of autonomic and neuroendocrine functions: a review. Curr. Neuropharmacol. 11, 141-159.

Crestani, C.C., Alves, F.H., Tavares, R.F., Correa, F.M., 2009. Role of the bed nucleus of the stria terminalis in the cardiovascular responses to acute restraint stress in rats. Stress 12, 268-278.

Crestani, C.C., Tavares, R.F., Alves, F.H., Resstel, L.B., Correa, F.M., 2010b. Effect of acute restraint stress on the tachycardiac and bradycardiac responses of the baroreflex in rats. Stress 13, 61-72.
Dampney, R.A., 2015. Central mechanisms regulating coordinated cardiovascular and respiratory function during stress and arousal. Am. J Physiol. Regul. Integr. Comp. Physiol. 309, R429-R443.

Davis, M., Walker, D.L., Miles, L., Grillon, C., 2010. Phasic vs sustained fear in rats and humans: role of the extended amygdala in fear vs anxiety. Neuropsychopharmacology 35, 105-135.

Dong, H.W., Petrovich, G.D., Swanson, L.W., 2001a. Topography of projections from amygdala to bed nuclei of the stria terminalis. Brain Res. Brain Res Rev. 38, 192-246.

Dong, H.W., Petrovich, G.D., Watts, A.G., Swanson, L.W., $2001 \mathrm{~b}$. Basic organization of projections from the oval and fusiform nuclei of the bed nuclei of the stria terminalis in adult rat brain. J. Comp. Neurol. 436, 430-455.

Dong, H.W., Swanson, L.W., 2004. Organization of axonal projections from the anterolateral area of the bed nuclei of the stria terminalis. J Comp. Neurol. 468, 277-298.

Dong, H.W., Swanson, L.W., 2006. Projections from bed nuclei of the stria terminalis, anteromedial area: cerebral hemisphere integration of neuroendocrine, autonomic, and behavioral aspects of energy balance. J Comp. Neurol. 494, 142-178.

Dos Reis, D.G., Fortaleza, E.A., Tavares, R.F., Correa, F.M., 2014. Role of the autonomic nervous system and baroreflex in stressevoked cardiovascular responses in rats. Stress 17, 362-372.

Figueiredo, H.F., Bruestle, A., Bodie, B., Dolgas, C.M., Herman, J. P., 2003. The medial prefrontal cortex differentially regulates stress-induced $\mathrm{c}$-fos expression in the forebrain depending on type of stressor. Eur. J. Neurosci. 18, 2357-2364.

Forray, M.I., Gysling, K., 2004. Role of noradrenergic projections to the bed nucleus of the stria terminalis in the regulation of the hypothalamic-pituitary-adrenal axis. Brain Res. Brain Res. Rev. 47, 145-160.

Fortaleza, E.A., Tavares, R.F., Correa, F.M., 2009. The medial amygdaloid nucleus modulates cardiovascular responses to acute restraint in rats. Neuroscience 159, 717-726.

Garthwaite, J., 2008. Concepts of neural nitric oxide-mediated transmission. Eur. J Neurosci. 27, 2783-2802.

Gouveia, M.K., Miguel, T.T., Busnardo, C., Scopinho, A.A., Correa, F. M., Nunes-de-Souza, R.L., Crestani, C.C., 2016. Dissociation in control of physiological and behavioral responses to emotional stress by cholinergic neurotransmission in the bed nucleus of the stria terminalis in rats. Neuropharmacology 101, 379-388.

Gray, T.S., Magnuson, D.J., 1987. Neuropeptide neuronal efferents from the bed nucleus of the stria terminalis and central amygdaloid nucleus to the dorsal vagal complex in the rat. J. Comp. Neurol. 262, 365-374.

Gross, C.T., Canteras, N.S., 2012. The many paths to fear. Nat. Rev. Neurosci. 13, 651-658.

Guimaraes, F.S., Beijamini, V., Moreira, F.A., Aguiar, D.C., de Lucca, A.C., 2005. Role of nitric oxide in brain regions related to defensive reactions. Neurosci. Biobehav. Rev. 29, 1313-1322.

Gungor, N.Z., Pare, D., 2016. Functional heterogeneity in the bed nucleus of the stria terminalis. J. Neurosci. 36, 8038-8049.

Hofmann, F., Feil, R., Kleppisch, T., Schlossmann, J., 2006. Function of cGMP-dependent protein kinases as revealed by gene deletion. Physiol. Rev. 86, 1-23.

Hott, S.C., Gomes, F.V., Fabri, D.R., Reis, D.G., Crestani, C.C., Correa, F.M., Resstel, L.B., 2012. Both alpha1- and beta1adrenoceptors in the bed nucleus of the stria terminalis are involved in the expression of conditioned contextual fear. Br. J Pharmacol. 167, 207-221.

Hott, S.C., Gomes, F.V., Uliana, D.L., Vale, G.T., Tirapelli, C.R., Resstel, L.B., 2017. Bed nucleus of the stria terminalis NMDA receptors and nitric oxide modulate contextual fear conditioning in rats. Neuropharmacology 112, 135-143.

Huang, P.L., Dawson, T.M., Bredt, D.S., Snyder, S.H., Fishman, M. C., 1993. Targeted disruption of the neuronal nitric oxide synthase gene. Cell 75, 1273-1286. 
Lebow, M.A., Chen, A., 2016. Overshadowed by the amygdala: the bed nucleus of the stria terminalis emerges as key to psychiatric disorders. Mol. Psychiatry 21, 450-463.

Martins-Pinge, M.C., Mueller, P.J., Foley, C.M., Heesch, C.M., Hasser, E.M., 2012. Regulation of arterial pressure by the paraventricular nucleus in conscious rats: interactions among glutamate, GABA, and nitric oxide. Front Physiol. 3, 490.

Morrison, S.F., 2001. Differential control of sympathetic outflow. Am. J Physiol. Regul. Integr. Comp. Physiol. 281, R683-R698.

Myers, B., 2017. Corticolimbic regulation of cardiovascular responses to stress. Physiol. Behav. 172, 49-59.

Myers, B., Mark Dolgas, C., Kasckow, J., Cullinan, W.E., Herman, J. P., 2014. Central stress-integrative circuits: forebrain glutamatergic and GABAergic projections to the dorsomedial hypothalamus, medial preoptic area, and bed nucleus of the stria terminalis. Brain Struct. Funct. 219, 1287-1303.

Patel, K.P., Zheng, H., 2012. Central neural control of sympathetic nerve activity in heart failure following exercise training. Am. J Physiol. Heart Circ. Physiol. 302, H527-H537.

Paxinos, G., Watson, C., 1997. The Rat Brain in Stereotaxic Coordinates 3rd ed. Academic Press, Sidney, Australia.

Prast, H., Philippu, A., 2001. Nitric oxide as modulator of neuronal function. Prog. Neurobiol. 64, 51-68.

Resstel, L.B., Alves, F.H., Reis, D.G., Crestani, C.C., Correa, F.M., Guimaraes, F.S., 2008. Anxiolytic-like effects induced by acute reversible inactivation of the bed nucleus of stria terminalis. Neuroscience 154, 869-876.
Rosen, J.B., 2004. The neurobiology of conditioned and unconditioned fear: a neurobehavioral system analysis of the amygdala. Behav. Cogn. Neurosci. Rev. 3, 23-41.

Rybalkin, S.D., Yan, C., Bornfeldt, K.E., Beavo, J.A., 2003. Cyclic GMP phosphodiesterases and regulation of smooth muscle function. Circ. Res 93, 280-291.

Silva, M., Aguiar, D.C., Diniz, C.R., Guimaraes, F.S., Joca, S.R., 2012. Neuronal NOS inhibitor and conventional antidepressant drugs attenuate stress-induced fos expression in overlapping brain regions. Cell Mol. Neurobiol. 32, 443-453.

Stern, J.E., Li, Y., Zhang, W., 2003. Nitric oxide: a local signalling molecule controlling the activity of pre-autonomic neurones in the paraventricular nucleus of the hypothalamus. Acta Physiol. Scand. 177, 37-42.

Tavares, R.F., Correa, F.M., Resstel, L.B., 2009. Opposite role of infralimbic and prelimbic cortex in the tachycardiac response evoked by acute restraint stress in rats. J. Neurosci. Res. 87, 2601-2607.

Ulrich-Lai, Y.M., Herman, J.P., 2009. Neural regulation of endocrine and autonomic stress responses. Nat. Rev. Neurosci. 10, 397-409.

Vianna, D.M., Carrive, P., 2005. Changes in cutaneous and body temperature during and after conditioned fear to context in the rat. Eur. J. Neurosci. 21, 2505-2512.

Vincent, S.R., Kimura, H., 1992. Histochemical mapping of nitric oxide synthase in the rat brain. Neuroscience 46, 755-784.

Zhou, L., Zhu, D.Y., 2009. Neuronal nitric oxide synthase: structure, subcellular localization, regulation, and clinical implications. Nitric Oxide 20, 223-230. 